\begin{tabular}{l}
\hline Access this article online \\
\hline Quick Response Code: \\
\hline Website: \\
www.jponline.org \\
\hline DOI: \\
10.4103/JLP.JLP_111_19 \\
\hline
\end{tabular}

Department of

Microbiology, Sri Ramachandra Institute of Higher Education and Research, Chennai, Tamil Nadu, India

Address for correspondence: Ms. Poothakuzhiyil Remya,

Department of Microbiology, Sri Ramachandra Institute of Higher Education and Research, Porur,

Chennai - 600 116,

Tamil Nadu, India. E-mail: remmoos@gmail.

Submission: 09-07-2019 Accepted: 24-11-2019

\title{
Prevalence and clonal relatedness of NDM and OXA-48-producing Klebsiella pneumoniae in a tertiary care hospital in South India
}

\author{
Poothakuzhiyil Remya, Mariappan Shanthi, Uma Sekar
}

\begin{abstract}
:
BACKGROUND: Carbapenems are used for the treatment of serious infections caused by multidrug-resistant Klebsiella pneumoniae. Resistance to carbapenems in K. pneumoniae is mainly due to metallo-beta-lactamases (NDM, IMP, and VIM) and class D oxacillinase (OXA-48-like).
\end{abstract}

AIM AND OBJECTIVE: This study was undertaken to detect the genes encoding for carbapenemase in $K$. pneumoniae and to determine the clonal relatedness of selected isolates of $K$. pneumoniae producing NDM and OXA-48 by pulsed-field gel electrophoresis method (PFGE).

MATERIALS AND METHODS: The isolates were collected over a period of 1 year. A total of 370 clinically significant, nonduplicate isolates of $K$. pneumoniae were included in this study. Phenotypic tests for the detection of carbapenemases were performed for all the isolates. Polymerase chain reaction (PCR) was carried out for the detection of carbapenemase genes such as $b a_{\mathrm{KPC}}, b a_{\mathrm{IMP}}, \mathrm{bla}_{\mathrm{VIM}}$, $b / a_{\mathrm{NDM}}$, and $b l a_{\mathrm{OXA}-48}$. PFGE was performed, and the PFGE profiles were analyzed and compared using BioNumerics version 7.6.

RESULTS: Of the 370 isolates of $K$. pneumoniae, carbapenemase genes were detected in $13.78 \%(51 / 370)$. bla $a_{\mathrm{OXA}-48}$ was the prevalent gene detected followed by $b / a_{\mathrm{NDM}}$ and $b / a_{\mathrm{KPC}}$. Thirty strains of $K$. pneumoniae selected by PFGE analysis were divided into five clusters (A, B, C, D, and E). Cluster $C$ was the major type detected carrying $b / a_{\mathrm{NDM}}$ and $b / a_{\mathrm{OXA}-48}$ genes.

CONCLUSION: $b l a_{\mathrm{OXA}-48}$ was the most prevalent gene detected in this study. PCR is useful in detecting carbapenemase genes, especially $b a_{\mathrm{NDM}}$, which may show false susceptibility to carbapenems. There was no direct correlation detected between PFGE profiles and antibiotic susceptibility pattern. PFGE has revealed the genomic diversity among isolates, thereby suggesting heterogeneity in strain circulation within intensive care unit and wards of the hospital. Monitoring and molecular typing is essential to curtail the spread of multidrug-resistant strains and control the outbreaks of infection.

Key words:

Carbapenemase, clonal relatedness, genotypic tests, Klebsiella pneumoniae, phenotypic tests, prevalence

\section{Introduction}

Tebsiella pneumoniae causes pneumonia, septicemia, urinary tract infection, and device-associated infection. ${ }^{[1]}$ Carbapenems are used for the treatment of severe infections caused by multidrug-resistant

This is an open access journal, and articles are distributed under the terms of the Creative Commons Attribution-NonCommercial-ShareAlike 4.0 License, which allows others to remix, tweak, and build upon the work non-commercially, as long as appropriate credit is given and the new creations are licensed under the identical terms.

For reprints contact: reprints@medknow.com
Gram-negative bacteria in clinical settings. Increase in the usage of carbapenems creates a selective pressure in bacteria, leading to the production of carbapenemase enzymes and destruction of carbapenems. ${ }^{[1,2]}$ Few other factors that contribute to carbapenem resistance include the overproduction of ESBLs or AmpC beta-lactamases combined with porin loss. ${ }^{[3]}$

How to cite this article: Remya $P$, Shanthi $M$, Sekar U. Prevalence and clonal relatedness of NDM and OXA-48-producing Klebsiella pneumoniae in a tertiary care hospital in South India. J Lab Physicians 2019;11:312-6. 
The most important carbapenemases identified in $K$. pneumoniae are class A K. pneumoniae carbapenemase (KPC), class B metallo-beta-lactamase (MBL) represented mainly by New Delhi MBL (NDM), imipenemase (IMP), verona integron mediated (VIM), and class D beta-lactamase, oxacillinase (OXA-48 like). ${ }^{[4,5]}$

Class B MBL (NDM, IMP, and VIM) exhibits a wide spectrum of activity against penicillin, cephalosporins, and carbapenems but spare aztreonam. They are inhibited by chelating agents such as ethylenediaminetetraacetic acid (EDTA). Class D beta-lactamases (OXA-48 like) hydrolyze carbapenems weakly and are poorly inhibited by clavulanic acid. ${ }^{[3]}$ Class A KPCs are plasmid encoded and hydrolyze carbapenem more effectively than other beta-lactam antibiotics. ${ }^{[5,6]}$

The emergence and dissemination of carbapenemase-producing $K$. pneumoniae is a matter of concern. Early detection of carbapenemase-producing bacteria in the initial stage of infection is essential to prevent outbreaks. ${ }^{[1]}$ Their rapid dissemination poses a threat to patient care. Study of clonal relatedness is necessary to understand their epidemiology, for the early implementation of infection control interventions, and to bring about efficient containment of cross transmission. Pulsed-field gel electrophoresis (PFGE) is a useful method for epidemiological tracing. ${ }^{[7]}$ This study was undertaken to detect the genes encoding for carbapenemase in K. pneumoniae and to determine the clonal relatedness of selected isolates of K. pneumoniae producing NDM and OXA-48.

\section{Materials and Methods}

\section{Bacterial isolates}

The study included 370 clinically significant, nonduplicate isolates of K. pneumoniae, collected over a period of 1 year (August 2014 to July 2015). The sources of isolates were urine (170), exudative specimens (132), and respiratory secretions such as bronchial wash, endotracheal aspirate, pleural fluid (38), and blood (30).

The isolates were identified up to species level by automated system (VITEK2 GN-card; bioMerieux, Brussels, Belgium) and/or standard biochemical tests. ${ }^{[8]}$

\section{Antibiotic susceptibility testing}

Antibiotic susceptibility testing was done by Kirby-Bauer disc diffusion method as per the Clinical and Laboratory Standards Institute (CLSI) guidelines. ${ }^{[9]}$ The antibiotics tested were cefotaxime $(30 \mu \mathrm{g})$, ceftazidime (30 $\mu \mathrm{g})$, amikacin $(30 \mu \mathrm{g})$, ciprofloxacin $(5 \mu \mathrm{g})$, piperacillin/ tazobactam $(100 \mu \mathrm{g} / 10 \mu \mathrm{g})$, and imipenem $(10 \mu \mathrm{g})$ (Himedia Laboratories, Mumbai, Maharashtra, India). ATCC Escherichia coli 25922 was used as control strain.
The clinical history of the patients was sought from the medical records.

\section{Determination of minimum inhibitory concentration}

Minimum inhibitory concentration (MIC) to imipenem (Sigma-Aldrich, Bangalore, Karnataka, India) was determined by agar dilution method (range: 0.03$128 \mu \mathrm{g} / \mathrm{ml}$ ) according to the CLSI guidelines. ${ }^{[9]}$

\section{Phenotypic tests}

Modified Hodge test (MHT) was performed to screen for the production of carbapenemases. Screening for MBL was done by inhibitor-based disc diffusion method using EDTA as inhibitor. ${ }^{[9,10]}$

\section{Molecular methods}

Detection of carbapenemase genes by multiplex polymerase chain reaction

Template DNA was extracted from the isolates by boiling method. All the isolates were tested for $b l a_{\mathrm{KPC}}$ $b l a_{\mathrm{NDM}^{\prime}} b l a_{\mathrm{IMP}}, b l a_{\mathrm{VIM}^{\prime}}$ and $b l a_{\mathrm{OXA}-48}$ genes by multiplex polymerase chain reaction (PCR) with primers used in earlier studies. ${ }^{[11]}$ Previously characterized strains were used as positive control.

\section{DNA sequencing}

PCR-positive amplicons were purified and sequenced by big dye 3.1 cycle sequencing kit using the Sanger AB13730XL DNA analyzing instrument (Sci Genome, Cochin, Kerala, India). The nucleotide sequences analyzed were compared with the sequence available at the National Centre for Biotechnology information website (www.ncbi.nIm.nih.gov). Sequences obtained in this study were submitted to GenBank with the following accession numbers KY678246 (NDM-1), KY678247 (OXA-48), and KY364013 (KPC).

\section{Pulsed-field gel-electrophoresis}

PFGE was performed on the thirty selected isolates with modifications. ${ }^{[12]}$ The isolates were selected based on the location of the source patients, time of isolation, and the presence of carbapenemase genes $b l a_{\mathrm{NDM}}$ and/or $b l a_{\text {OXA-48 }}$. They were representative of pathogens isolated from the various facilities of the hospital. Genomic DNA was prepared in agarose blocks and digested with the restriction enzyme XbaI. The DNA fragments were separated by the use of the CHEF-DR III System (BioRad laboratories, Gurgaon, Haryana, India) at $6 \mathrm{~V} / \mathrm{cm}$ for $20 \mathrm{~h}, 14^{\circ} \mathrm{C}$, and $120^{\circ} \mathrm{C}$ included angle, with the pulse time increasing from 5 to $30 \mathrm{~s}$ and 2.2 to $45 \mathrm{~s}$. The PFGE profiles were analyzed and compared using BioNumerics version 7.6 (Applied Maths, Sint-Martens-Latem, Belgium). Pattern interpretation was also carried out according to the Tenover criteria. ${ }^{[13]}$ Cluster analysis was done with the unweighted pair group method 
with arithmetic mean and Dice coefficient. Isolates that exhibited a PFGE profile with $\geq 80 \%$ similarity were considered as closely related strains. ${ }^{[14,15]}$

\section{Results}

Among the 370 isolates of K. pneumoniae, 13.24\% (49/370) were resistant to imipenem. $\mathrm{MIC}_{50}$ and $\mathrm{MIC}_{90}$ were $0.125 \mu \mathrm{g} / \mathrm{mL}$ and $4 \mu \mathrm{g} / \mathrm{mL}$, respectively.

The susceptibility of the study isolates to other antimicrobial agents was as follows: amikacin $(82.16 \%)$, piperacillin/tazobactam $(80.27 \%)$, ciprofloxacin $(62.97 \%)$, ceftazidime and cefotaxime (50.54\%).

Phenotypic screening for carbapenemase production by MHT was positive in $24.86 \%(92 / 370)$ of isolates. False positivity was detected in 47 isolates. Nearly $6.75 \%(25 / 370)$ of the isolates tested positive for MBL screen and false positivity was found in 20 isolates.

Among 49 carbapenem-resistant isolates, 47 carried one or more carbapenemase genes looked for in this study. In two isolates, none of the genes were detected.

Of the 370 study isolates, carbapenemase genes were found in $13.78 \%(51 / 370)$ of the isolates. The distribution of the genes was as follows $b l a_{\mathrm{OXA}-48}$ alone (34), $b l a_{\mathrm{NDM}}$ alone (9), $b l a_{\mathrm{KPC}}(1)$, and $b l a_{\mathrm{NDM}}+b l a_{\mathrm{OXA} 48}(7)$. Notably, four isolates that were susceptible to imipenem harbored the $b l a_{\mathrm{NDM}}$ gene. This is depicted in Table 1.

\section{Clonal relatedness analyzed by pulsed-field gel} electrophoresis

According to the PFGE dendrogram pattern [Figure 1], thirty strains of $K$. pneumoniae were divided into five clusters (A, B, C, D, and E). The number of isolates in each cluster and the genes detected is depicted in Table 2. Cluster $C$ was the major type observed with 13 strains. Of them, five were from patients admitted to a single multidisciplinary intensive care unit (MD-ICU), whereas the others (8) were from patients in the non-ICU settings. Cluster A and D had 4 and 3 strains, respectively. Cluster $B$ had five similar strains, of which two were from the MD-ICU. In cluster E, there were five strains.

\section{Discussion}

Carbapenems are an important class of antimicrobials used for the treatment of serious life-threatening infections. One of the important established nosocomial pathogens is K. pneumoniae belonging to the family Enterobacteriaceae. In view of the increased risk of infection with carbapenem-resistant K. pneumoniae, especially in the hospitalized, it is essential to identify their genotypic characteristics. ${ }^{[16,17]}$
Table 1: Carbapenemase-encoding genes and their susceptibility pattern with imipenem

\begin{tabular}{lcc}
\hline Carbapenemase genes detected (51) & \multicolumn{2}{c}{ MIC to imipenem } \\
\cline { 2 - 3 } & Susceptible & Resistant \\
\hline OXA-48 (34) & 0 & 34 \\
NDM (9) & 4 & 5 \\
KPC (1) & 0 & 1 \\
Both NDM+OXA-48 (7) & 0 & 7 \\
\hline
\end{tabular}

MIC=Minimum inhibitory concentration, $\mathrm{OXA}=\mathrm{Oxacillinase,} \mathrm{NDM=New}$ Delhi metallo-beta-lactamase, KPC=Klebsiella pneumoniae carbapenemase

Table 2: Distribution of the different clusters and the genes detected

\begin{tabular}{|c|c|c|}
\hline Cluster & Number of isolates & Genes detected \\
\hline$A$ & 4 & $b / a_{\mathrm{OXA}-48(4)}$ \\
\hline B & 5 & $b / a_{\mathrm{OXA}-48(5)}$ \\
\hline C & 13 & $\begin{array}{l}b l a_{\mathrm{NDM}}+b l a_{\mathrm{OXA}-48}(1) \\
\text { bla }_{\mathrm{NDM}}(2) \\
\text { bla }_{\mathrm{OXA}-48}(10)\end{array}$ \\
\hline D & 3 & $b l a_{\mathrm{OXA}-48(3)}$ \\
\hline$E$ & 5 & $\begin{array}{l}b l a_{\mathrm{OXA}-48}(4) \\
\text { bla }_{\mathrm{NDM}}+b / a_{\mathrm{OXA}-48}(1)\end{array}$ \\
\hline
\end{tabular}

$\mathrm{OXA}=\mathrm{Oxacillinase}, \mathrm{NDM}=\mathrm{New}$ Delhi metallo-beta-lactamase

The MHT and MBL screen test was positive in 92 and 25 isolates, respectively. However, the carbapenemase-encoding genes were detected in 45 and 6 isolates only. False-positive MHT and MBL screen test observed could be due to the other carbapenemases, which were not looked for in this study. ${ }^{[18]}$

Among the 49 carbapenem-resistant isolates, 47 carried carbapenemase genes. Two isolates were negative for any of the carbapenemase genes which were looked for. This can be attributed to ESBL production with porin loss or hyperproduction of AmpC beta lactamase or other carbapenemases. ${ }^{[5]}$

In this study, the most prevalent carbapenemase gene detected was $b l a_{\mathrm{OXA}-48}$ followed by $b l a_{\mathrm{NDM}}$ and $b l a_{\mathrm{KPC}}$. This result is in agreement with the previous studies stating that $b l a_{\text {OXA-48 }}$ is becoming the most prevalent carbapenemase gene in K. pneumoniae. ${ }^{[19-21]}$ Absence of IMP and VIM is notable.

$b l a_{\mathrm{NDM}}$ has been detected in carbapenem-susceptible isolates also. This phenomenon can lead to improper treatment and therapeutic failure. Therefore, K. pneumoniae exhibiting resistance to third-generation cephalosporins have to be screened for the presence of $b l a_{\mathrm{NDM}}$ to prevent inappropriate therapy ${ }^{[18]}$

The PFGE analysis divided carbapenemase-producing K. pneumoniae into five distinct clusters. Cluster C (13) was the major one detected in our study. All the isolates in this cluster carried $b l a_{\mathrm{NDM}}$ and $b l a_{\mathrm{OXA}-48}$ genes. Similarly, all isolates in cluster E carried $b l a_{\mathrm{NDM}}$ and $b l a_{\mathrm{OXA}-48}$. 


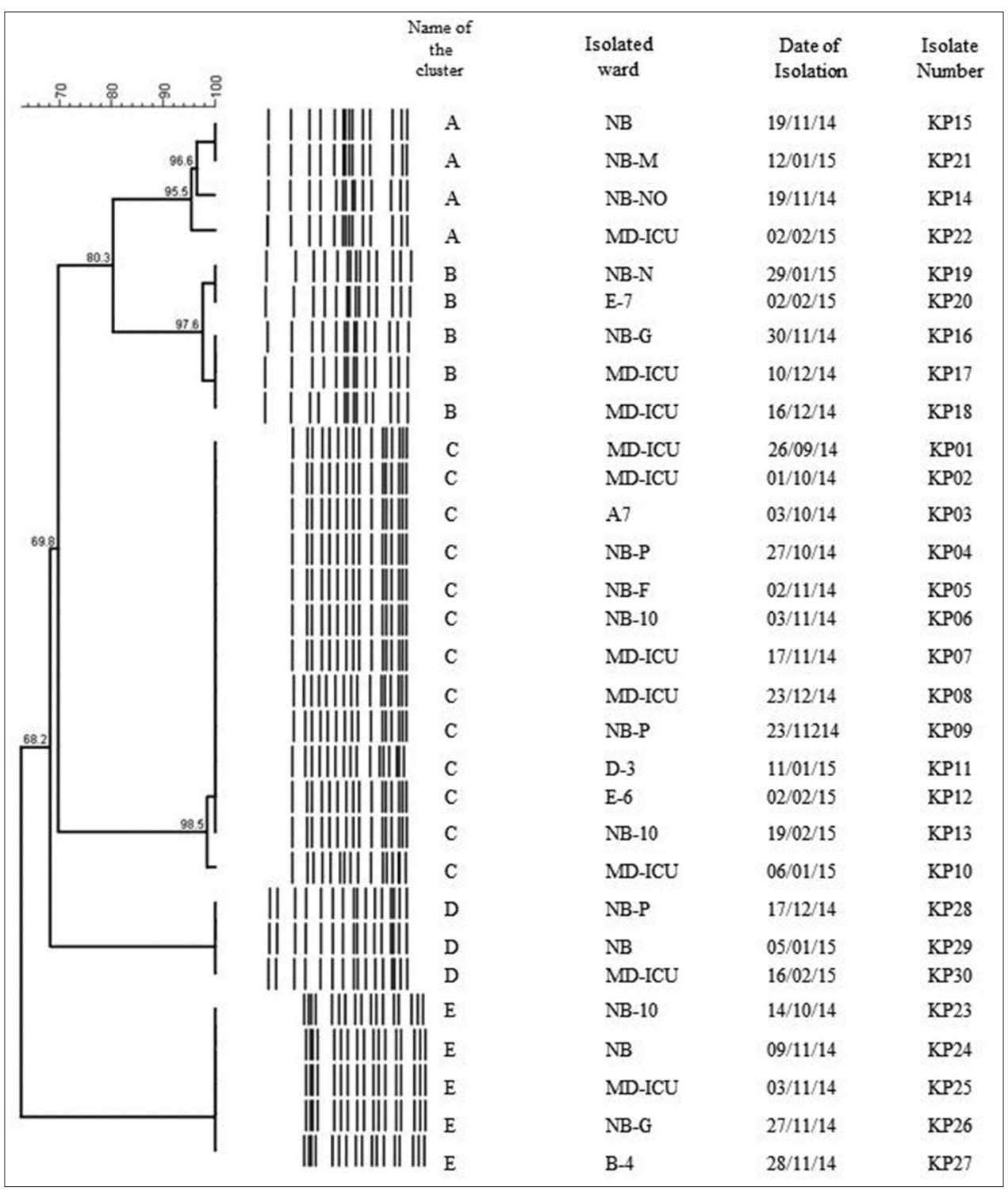

Figure 1: Dendrogram analysis. Dendrogram generated with the BioNumerics software, demonstrating the relatedness of fingerprints of thirty selected strains of Klebsiella pneumoniae. The phylogenetic tree was constructed using the Dice coefficient and unweighted pair group method with arithmetic mean clustering. A genetic similarity index scale is shown in the left of the dendrogram. Pulsed-field gel electrophoresis types, isolated ward, date of isolation, and strain numbers are included along each pulsed-field gel electrophoresis lane

In a study from Romania, the performance of PFGE in 65 carbapenemase-producing K. pneumoniae isolates identified eight PFGE types, and cluster C (35) was the predominant clone detected..$^{[22]}$

In the present study, clusters $\mathrm{A}, \mathrm{B}$, and D harbored $b l a_{\mathrm{OXA}-48}$ only. There have been reports about the more prevalent clusters carrying OXA-48. ${ }^{[23]}$

Clonally related strains carrying different types of carbapenemase genes can be due to the acquisition of the resistance traits after the clonal spread had occurred. ${ }^{[24]}$

There was no direct correlation between PFGE profiles and antibiotic susceptibility pattern in this study. Isolates exhibiting identical antibiotic susceptibility pattern belonged to different PFGE types. Most of the isolates that were unrelated on the basis of susceptibility pattern had similar PFGE patterns. A similar type of result was observed in a study from Tunisia. ${ }^{[25]}$ This emphasizes the fact that the phenotypic similarity in terms of and antibiotic susceptibility is not an optimal method for clonal identification.

Identical PFGE patterns associated with strains from different facilities of the hospital was encountered. This is probably attributable to transfer of patients within hospital.

\section{Conclusion}

PFGE exhibited five different clusters of carbapenemase genes carrying K. pneumoniae, and they were disseminated 
in MD-ICU and different wards. The present study had a high prevalence of $b l a_{\text {OxA-48 }}$ carbapenemase gene. PCR is useful for detecting carbapenemase genes, especially $b l a_{\mathrm{NDM}}$ which may appear falsely susceptible to carbapenems. Prompt identification helps to formulate the optimal treatment plans and prevent nosocomial outbreaks. There was no direct correlation between PFGE profiles and antibiotic susceptibility pattern. PFGE has revealed the genomic diversity among isolates, thereby suggesting heterogeneity in strain circulation within ICU and wards of the hospital. Monitoring and molecular typing is essential to curtail the spread of multidrug-resistant strains and control the outbreaks of infection.

\section{Acknowledgment}

The authors would like to thank Dr. Sujatha Sistla, Dr. Madhan Sugumar, and Dr. Rajesh Amberpet, Department of Microbiology, JIPMER, Puducherry, for their technical support in carrying out PFGE.

All the authors are grateful for the financial assistance provided by Sri Ramachandra Institute of Higher Education and Research as Founder Chancellor Fellowship.

\section{Financial support and sponsorship}

This study was supported by the Founder Chancellor Sri Ramasamy Udayar Fellowship, provided by Sri Ramachandra Institute of Higher Education and Research.

\section{Conflicts of interest}

There are no conflicts of interest.

\section{References}

1. Hayder N,Hasan Z, Afrin S, Noor R. Determination of the frequency of carbapenemase producing Klebsiella pneumoniae isolates in Dhaka city, Bangladesh. Stamford J Microbiol 2012;2:28-30.

2. Zhang R, Liu L, Zhou H, Chan EW, Li J, Fang Y, et al. Nationwide surveillance of clinical carbapenem-resistant Enterobacteriaceae (CRE) strains in China. E Bio Med 2017;19:98-106.

3. Datta P, Gupta V, Garg S, Chander J. Phenotypic method for differentiation of carbapenemases in Enterobacteriaceae: Study from North India. Indian J Pathol Microbiol 2012;55:357-60.

4. MariappanS,SekarU,Kamalanathan A.Carbapenemase-producing Enterobacteriaceae: Risk factors for infection and impact of resistance on outcomes. Int J Appl Basic Med Res 2017;7:32-9.

5. Nordmann P, Naas T, Poirel L. Global spread of carbapenemase-producing Enterobacteriaceae. Emerg Infect Dis 2011;17:1791-8.

6. Remya P, Shanthi M, Sekar U. Prevalence of KPC and its occurrence with other beta-lactamases in Klebsiella pneumoniae. J Lab Physicians 2018;10:387-91.

7. Nematzadeh S, Shahcheraghi F, Feizabadi MM, Nikbin VS, Nasehi L. Molecular characterization of CTX-M $\beta$-lactamases among Klebsiella pneumoniae isolated from patients at Tehran hospitals. Indian J Med Microbiol 2011;29:254-7.

8. Collee JG, Miles RS, Matt B. Test for identification of bacteria. In: Collee JG, Fraser AG, Marmion BP, Simmons A, editors. Mackie and McCartney Practical Medical Microbiology. $14^{\text {th }}$ ed., Ch. 7. Edinburgh: Churchill Livingstone; 1996. p. 131-49.

9. Clinical and Laboratory Standards Institute. Performance Standards for Antimicrobial Susceptibility Testing. $25^{\text {th }}$ Informational Supplement Document M100-S25. Wayne: Clinical and Laboratory Standards Institute; 2015.

10. Abiramasundari VK, Sekar U, Shanthi M, Arunagiri K. Detection of carbapenemase production in Klebsiella pneumoniae in a tertiary care centre. Int J Pharm Bio Sci 2015;6:847-56.

11. Poirel L, Walsh TR, Cuvillier V, Nordmann P. Multiplex PCR for detection of acquired carbapenemase genes. Diagn Microbiol Infect Dis 2011;70:119-23.

12. Gautom RK. Rapid pulsed-field gel electrophoresis protocol for typing of Escherichia coli O157:H7 and other gram-negative organisms in 1 day. J Clin Microbiol 1997;35:2977-80.

13. Tenover FC, Arbeit RD, Goering RV, Mickelsen PA, Murray BE, Persing DH, et al. Interpreting chromosomal DNA restriction patterns produced by pulsed-field gel electrophoresis: Criteria for bacterial strain typing. J Clin Microbiol 1995;33:2233-9.

14. Tseng IL, Liu YM, Wang SJ, Yeh HY, Hsieh CL, Lu HL, et al. Emergence of carbapenemase producing Klebsiella Pneumonia and Spread of KPC-2 and KPC-17 in Taiwan: A nationwide study from 2011 to 2013. PLoS One 2015;10:e0138471.

15. Bi W, Liu H, Dunstan RA, Li B, Torres VV, Cao J, et al. Extensively Drug-Resistant Klebsiella pneumoniae causing nosocomial bloodstream Infections in China: Molecular investigation of antibiotic resistance determinants informing therapy and clinical outcomes. Front Microbiol 2017;8:1230.

16. Poirel L, Potron A, Nordmann P. OXA-48-like carbapenemases: The phantom menace. J Antimicrob Chemother 2012;67:1597-606.

17. Hosseinzadeh Z, Sedigh Ebrahim-Saraie H, Sarvari J, Mardaneh J, Dehghani B, Rokni-Hosseini SM, et al. Emerge of bla NDM-1 and bla OXA-48-like harboring carbapenem-resistant Klebsiella pneumoniae isolates from hospitalized patients in Southwestern Iran. J Chin Med Assoc 2018;81:536-40.

18. Shanthi M, Sekar U, Sowmiya M, Malathi J, Kamalanathan A, Sekar B, et al. Clonal diversity of New Delhi metallobetalactamase-1 producing Enterobacteriaceae in a tertiary care centre. Indian J Med Microbiol 2013;31:237-41.

19. Veeraraghavan B, Shankar C, Karunasree S, Kumari S, Ravi R, Ralph R. Carbapenem resistant Klebsiella pneumoniae isolated from bloodstream infection: Indian experience. Pathog Glob Health 2017;111:240-6.

20. Sharma A, Bakthavatchalam YD, Gopi R, Anandan S, Verghese VP, Veeraraghavan B. Mechanisms of Carbapenem Resistance in K. pneumoniae and E. coli from Bloodstream Infections in India. J Infect Dis Ther 2016; 4:293.

21. Pragasam AK, Sahni RD, Anandan S, Sharma A, Gopi R, Hadibasha N, et al. A pilot study on carbapenemase detection: Do we see the same level of agreement as with the CLSI observations. J Clin Diagn Res 2016;10:DC09-13.

22. Lixandru BE, Cotar AI, Straut M, Usein CR, Cristea D, Ciontea S, et al. Carbapenemase-producing Klebsiella pneumoniae in Romania: A six-month survey. PLoS One 2015;10:e0143214.

23. Solgi H, Badmasti F, Aminzadeh Z, Giske CG, Pourahmad M, Vaziri $\mathrm{F}$, et al. Molecular characterization of intestinal carriage of carbapenem-resistant Enterobacteriaceae among inpatients at two Iranian university hospitals: first report of co-production of blaNDM-7 and blaOXA-48. Eur J Clin Microbiol Infect Dis 2017;36:2127-35.

24. Zujić Atalić V, Bedenić B, Kocsis E, Mazzariol A, Sardelić S, Barišić $\mathrm{M}$, et al. Diversity of carbapenemases in clinical isolates of Enterobacteriaceae in Croatia - The results of a multicentre study. Clin Microbiol Infect 2014;20:O894-903.

25. Ben-Hamouda T, Foulon T, Ben-Cheikh-Masmoudi A, Fendri C, Belhadj O, Ben-Mahrez K. Molecular epidemiology of an outbreak of multiresistant Klebsiella pneumoniae in a Tunisian neonatal ward. J Med Microbiol 2003;52:427-33. 